\title{
Establishing a Causal Link between Ankylosing Spondylitis and Inflammatory Bowel Disease: A Review of the Literature
}

Jaclyn Rivington, ${ }^{1}$ Michael Gillett . ${ }^{1}$

\begin{abstract}
The link between ankylosing spondylitis and inflammatory bowel disease is unclear, however it is hypothesized that there is a causal link between the inheritance of a human leukocyte antigen B27 allele and the development of inflammatory bowel disease symptoms in ankylosing spondylitis patients. Research articles assessing the relationship between ankylosing spondylitis, inflammatory bowel disease and the human leukocyte antigen B27 antigen were collected from the PubMed database. Patients expressing the human leukocyte antigen B27 allele have a demonstrated predisposition to developing symptoms of inflammatory bowel disease and sacroiliitis in ankylosing spondylitis. However, human leukocyte antigen B27 is considered to be just a contributing factor in the disease, as interleukin-23, natural killer cells, and alterations to the microbiome have also demonstrated an active role in the development of symptoms. More longitudinal studies using larger cohorts are needed to further substantiate a direct causal relationship between ankylosing spondylitis and inflammatory bowel disease.
\end{abstract}

Keywords: HLA-B27 Antigen; Spondylitis, Ankylosing; Inflammatory Bowel Diseases; Sacroiliitis; Killer Cells, Natural (Source: MeSH, NLM).

About the Author: Jaclyn Rivington is a fourth-year medical student at Saba University School of Medicine, graduating in 2017. She completed her undergraduate studies at Guelph University in Canada.

\section{Introduction}

Ankylosing spondylitis (AS) is a debilitating disease found in $0.5 \%$ of the population.' It is commonly diagnosed in young Caucasian men aged $20-40$ and is characterized by sacroiliitis and fusion of vertebrae. AS is classified as a seronegative arthropathy, which are arthropathies that involve the axial skeleton and are negative for rheumatoid factor. Other arthropathies include: psoriatic arthritis, reactive arthritis, and enteropathic arthritis. Diagnosis of AS is commonly delayed by 5-6 years due to the lack of specific biomarkers and variation in clinical presentation. ${ }^{2}$ Better understanding of the candidate genes and pathogenesis of this incapacitating disease will hopefully result in earlier diagnosis and more targeted treatment.

AS patients most commonly present with uveitis, aortitis or inflammatory bowel disease (IBD) in addition to classic symptoms of chronic lower back pain. Development of uveitis in AS patients appears to be correlated with disease duration, the theory being that chronic inflammation and immune disruption in AS leaves the patient more vulnerable to developing uveitis. ${ }^{3}$ However, the co-presentation of IBD and AS appears to be less chronological.

Only 5-10\% of AS patients present with overt IBD; conversely upwards of $60 \%$ of AS patients have subclinical gut inflammation when investigated through more invasive means such as ileocolonoscopy. ${ }^{4-6}$ One study found that nearly all patients with regional enteritis, along with the human leukocyte antigen (HLA-B27) allele, were prone to developing AS.? Numerous studies have further demonstrated the close relation between IBD and AS. ${ }^{8,9}$ Both of these diseases are currently posited as being autoimmune in etiology, and share some similar genes of interest such as IL-23. ${ }^{\circ 0}$ Furthermore, signs of gut inflammation are seen prior to the diagnosis of AS and thus may play a role in the etiologic pathway. ${ }^{3}$

AS has a strong genetic link. ${ }^{11,12}$ More than $90 \%$ of AS patients have the HLA-B27 allele, but its role in the underlying etiology remains unclear. There appears to be an interplay between not only the HLA-B27 genetic predisposition, but other genes, environmental and immunological factors. These will be outlined below and in Figure 1.

\section{Genetics}

HLA-B27 is a major histocompatibility complex (MHC) class 1 antigen that has an established link with AS. It plays a role in presenting self-antigens to $T$ cells. Research suggests that misfolding of the protein encoded by this allele leads to its accumulation in the endoplasmic reticulum (ER). ${ }^{4}$ This intracellular accumulation may then precipitate an inflammatory response seen both in the joints and in extra-articular sites of AS patients.

Recent Genome Wide Associated Studies (GWAS) have discovered two prospective pathways in the etiology of AS-interleukin 23/T-helper 17 cell (IL23/Th17) and endoplasmic reticulum aminopeptidase-1 (ERAP-1). IL23 is produced by antigen presenting cells and is responsible for upregulating Th17 cells. ${ }^{13}$ Th17 cells produce pro-inflammatory cytokines (IL17, IL22, TNF-alpha) and are linked to the development of autoimmune diseases. ${ }^{14} \mathrm{Hi}$ gher levels of Th17 cytokines have been measured in AS patients, and anti-TNF-alpha therapy has been shown to down-

${ }^{1}$ Saba University School of Medicine, Caribbean Netherlands. 
Figure 1. Major Contributors to the Development of Ankylosing Spondylitis

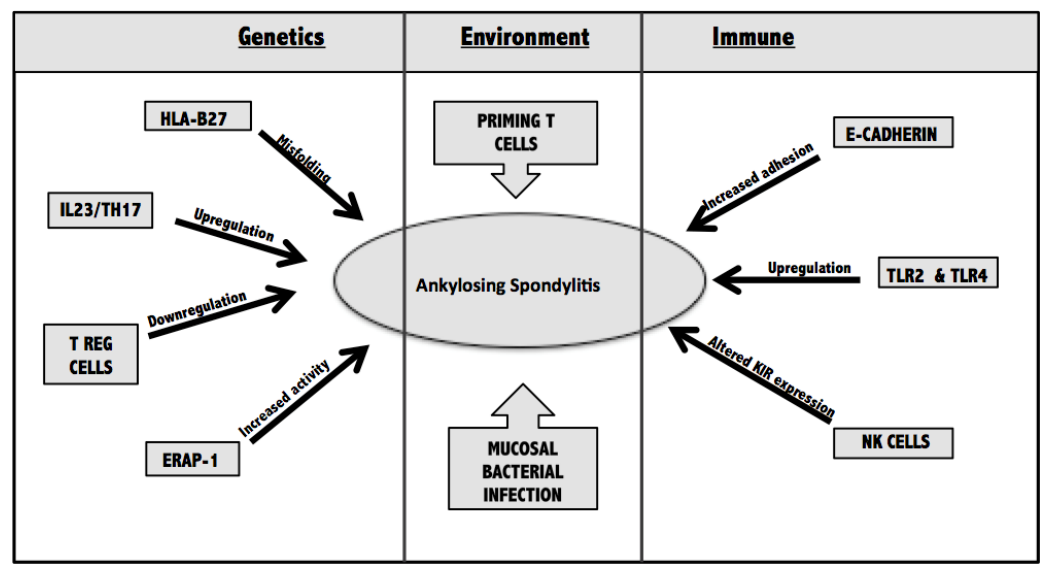

HLAB27=human leukocyte antigen B27; IL23=interleukin 23; Th17=T helper cell 17; T reg cell=T regulatory cell; TLR2=Toll-like Receptor 2; KIR=Killing Inhibitory Receptor; NK=Natural Killer cells.

regulate this cell population and provides beneficial therapy for AS patients. ${ }^{14,15}$ An upregulation in the Th17 pathway also results in a reciprocal down-regulation in the regulatory $T$ cell (Treg) pathway, which normally protects against autoimmune disease. ${ }^{16}$ The level of evidence supporting the role of the Th17 pathway in AS pathogenesis continues to increase-there have been similar findings in animal models and most recently with therapeutic monoclonal antibodies. ${ }^{17,18}$

The second pathway of interest is endoplasmic reticulum aminopeptidase 1 (ERAP-1), an aminopeptidase responsible for cleaving peptides in the ER before they are loaded into the MHC 1 . Recent observation demonstrates that ERAP-1 alterations only influence AS patients that are HLA-B27 positive. ${ }^{19}$ Patients with higher aminopeptidase activity have altered expression of free heavy chains (FHC) on the surface of their circulating monocytes. FHC's are commonly referred to as class one molecules without the B2 microglobulin. ${ }^{20}$ These FHC dimers are recognized on the surface by inhibitory killing immunoglobulin receptors (KIR) of NK cells, and will be further discussed in the Immune section. ${ }^{21}$

\section{Environment}

Alterations in gut microbiota is suspected of playing a role in gut inflammation in AS pathogenesis. Previous studies have shown molecular similarities between HLA-B27 and Klebsiella pneumoniae.22 Klebsiella and anti-Klebsiella antibodies have been isolated from the bowels of patients with active AS and parallel exacerbations were seen between Klebsiella levels and IBD symptoms. ${ }^{22-24}$

It is hypothesized that long-term inflammation of the intestinal mucosa caused by bacterial infections could eventually catalyze an inflammatory response within the joint. However, live bacteria have never been isolated from the synovium and chronic anti-bacterial treatment has been futile at slowing disease progression. A recent study suggests that, more conceivably, T cells are primed in the gut and then migrate to the synovium. ${ }^{24}$ Once in the synovium, cluster differentiation 163 (CD163) macrophages are activated and release a very specific cytokine profile, including high TNF-alpha and low IL10.25

\section{Immune system}

AS patients have shown increased permeability in the mucosal lining of their gastrointestinal tract, which is considered a first line, innate immune defense. ${ }^{26} \mathrm{E}$-cadherin, an epithelial junctional protein, may contribute to this mucosal disturbance. The down-regulation of E-cadherin is commonly associated with cancer metastasis, however, there has been recent proof of higher levels of this adhesion complex in patients with IBD and spondyloarthropathies. ${ }^{27}$

Alteration in the expression of Toll-like receptors (TLR4 and TLR2) in the gut mucosa as well as the synovium of patients with AS could indicate a link between the innate immune system and presentation of IBD in AS. ${ }^{28,29}$ TLR's are a family of membrane proteins that, when bound by a pathogen associated molecular pattern (PAMP), activate a pathway that mediates inflammation. This pathway is essential in the initiation of host defense. After TNF-alpha inhibitor therapy, down-regulation of TLR-4 and remittance of symptoms was observed which suggests a prominent role of this protein in AS and potential contribution to the etiology. ${ }^{28}$

A final immune regulatory mechanism that has been suggested is the alteration in natural killer (NK) cell defense. Killer immunoglobulin-like receptors (KIR) are found predominantly on NK cells, $\mathrm{T}$ cells and minor subsets of CD4 and CD8 cells. They act by binding to MHC class 1 and altering the cytokine profile to promote survival of the cell. ${ }^{30} \mathrm{KIR}^{\prime} \mathrm{s}$ are unique as they have the ability to recognize different HLA-class one allotypes, which could be linked to the AS association with HLA-B27. Haroon et al, 2012, demonstrated an increased risk associated with KIR3DL2 and a protective effect of KIRDL1. ${ }^{31}$ To date, KIRDL1 is the only KIR known to recognize and bind to the HLA-B alleles. ${ }^{32}$ Therefore, alterations to KIR expression could alter innate immune mechanisms of defense, predisposing patients to development of AS.

Current literature reveals a consistent genetic link between AS and HLA-B27, however further research has demonstrated that this is a very complex, multifactorial and oligogenic disease. The association of certain genes with disease is a first step in a full understanding of etiology, and current research aims to understand the sequence of pathogenesis to develop more targeted therapy. This paper will further explore the relationship of HLA-B27 with the extra-articular symptoms of IBD in AS. It is hypothesized that there is a causal link between the inheritance of an HLA-B27 allele and the development of IBD symptoms in AS patients.

\section{Search Strategy and Selection Criteria}

The PubMed database (01 January 2004 - 30 December 2014) was searched using the terms: "Ankylosing Spondylitis", "Inflammatory Bowel Disease" and "HLA-B27 Antigen". These terms were searched both as basic terms and "MeSH" terms. The author examined the titles and abstracts for articles that included: (1) Both IBD and Ankylosing Spondylitis in the abstract; (2) Human subjects, (3) Published in English, (4) Full reports (not just abstracts) and (5) Addressed the link and/or etiology of IBD and AS. Articles that did not meet these criteria were excluded. Full text articles were obtained and classified according to their study type. Articles included in the review 
can be found in Table 1. Studies were classified using the evidence table created by the authors, as shown in Table 2. The methodology used for reviewing articles for inclusion is outlined in Figure 2.

\section{Search Results}

Using the search criteria as outlined in the methods, the literature search provided 226 articles, all of which were reviewed. Based on the exclusion criteria, 10 of these articles were included for the purposes of this review. These 10 articles included six level-three case-control studies and four level-four cohort studies without controls. A summary of candidate genes and biomarkers which will be outlined in this review is available in Table 3.

\section{Genetics}

Ciccia et al (2014) investigated the mechanism of IL23 expression in a study of 30 HLA-B27 positive AS patients, 15 Crohn's Disease (CD) and 10 normal subjects. ${ }^{13}$ Sequential gut biopsies were taken from the subjects, then autophagy and unfolded

Table 1. Studies Evaluating the Genetics of Ankylosing Spondylitis

\begin{tabular}{|c|c|c|c|c|}
\hline Study & Study Design & $\begin{array}{l}\text { Level of } \\
\text { Evidence }\end{array}$ & Study Population & Therapy or Exposure \\
\hline $\begin{array}{l}\text { Ciccia et al } \\
(2014)\end{array}$ & $\begin{array}{l}\text { Case control } \\
\text { with controls }\end{array}$ & 3 & $\begin{array}{l}30 \text { AS patients (human } \\
\text { leukocyte antigen } \\
\text { (HLA-B27+)); } 15 \text { Crohn's } \\
\text { disease (CD) patients \& } \\
10 \text { normal subjects }\end{array}$ & $\begin{array}{l}\text { Consecutive gut biopsies were } \\
\text { analyzed for evidence of misfolding } \\
\text { of HLA-B27. Unfolded protein } \\
\text { response (UPR) and autophagy were } \\
\text { assessed via RT-PCR and IHC. This } \\
\text { was then compared to the regulation } \\
\text { of IL-23 expression on lamina propria } \\
\text { mononuclear cells (LPMCS). }\end{array}$ \\
\hline
\end{tabular}

$\begin{array}{llll}\begin{array}{l}\text { Duarte et al } \\ \text { (2014) }\end{array} & \begin{array}{l}\text { Prospective } \\ \text { Cohort }\end{array} & \begin{array}{l}\text { 1424 patients; } 235 \text { with } \\ \text { disease onset before } 16 \\ \text { years old }\end{array} & \begin{array}{l}\text { Analyze the characteristics of juveni- } \\ \text { le-onset spondyloarthritis (SpA) ( } 16 \\ \text { yr) with a group of adult-onset SpA } \\ \text { patients. }\end{array}\end{array}$

$\begin{array}{lll}\text { Wei et al Case control } & 3 & 475 \text { AS patients; } 475 \\ \text { (2013) } & & \text { healthy subjects in a }\end{array}$

$\begin{array}{lll}\begin{array}{l}\text { Matzkies et } \quad \text { Case control } \quad 3 \quad \\ \text { al (2012) }\end{array} & 39 \text { AS patients; } 42 \text { con- } \\ & \text { trols. Average age } 47, \\ & \text { average age duration } \\ & \text { was } 22 \text { years }\end{array}$

Skare et al Cross sectional 4 (2012)

\begin{tabular}{|llll}
\hline $\begin{array}{l}\text { D'Inca et al } \\
(2009)\end{array}$ & $\begin{array}{l}\text { Case control } \\
\text { with no } \\
\text { control }\end{array}$ & 4 & $\begin{array}{l}142 \text { UC patients; } 120 \text { CD } \\
\text { patients }\end{array}$ \\
\hline $\begin{array}{l}\text { Togrol et al } \\
(2009)\end{array}$ & Case control & 3 & $\begin{array}{l}\text { 30 AS patients; } 19 \\
\text { age and sex matched } \\
\text { controls }\end{array}$ \\
\hline
\end{tabular}

\begin{tabular}{llll}
$\begin{array}{l}\text { Orchard et } \\
\text { al (2008) }\end{array}$ & Cross sectional & 4 & 44 CD patients \\
& & & \\
$\begin{array}{l}\text { Aydin et al } \\
(2008)\end{array}$ & Case control & 3 & $\begin{array}{l}175 \text { patients with AS; } \\
47 \text { with undifferentia- } \\
\text { ted SpA; } 103 \text { healthy } \\
\text { controls }\end{array}$ \\
\hline
\end{tabular}

$\begin{array}{lll}\text { Turkcapar } & \begin{array}{l}\text { Case control } \\ \text { with no } \\ \text { et al (2006) }\end{array} & 4\end{array}$
Taiwanese population

1318 SpA patients; $65 \%$ white; $31.3 \%$ Brazilian; $3.7 \%$ mixed. $65.1 \%$ with AS; $18.3 \%$ psoriatic arthritis, $6.8 \%$ undifferentiated

\section{Investigating loci other than endo} plasmic reticulum aminopeptidase(ERAP-1) and HLA-B27 for AS susceptibility. A recent GWAS showed two potential loci 5914.3 and 12912 .

Sera were tested by ELISA for IBD-associated serologies (ANCA, anti-Cerevisiae Ab IgC C IgA, Anti-I2, Anti-0mpC and anti-CBir1). BASDAI was also completed for AS patients.

Did an array of tests and looked at other variables to determine whether ethnicity plays a role in the progression of spondyloarthropathies.

Looked at the prevalence of articular pain in IBD patients.

Analyzed HLA-B27, Anti-gliadin (AGA), ct endomysial antibodies (EMA). AGA positive patients were examined by a gastroduodenoscope.

Clinical evaluation of symptom questionnaire, rheumatological exam, HLA genotyping, MRI of sacroiliac joints.

Questioned for demographic features, BASDAI scores, BASRI and mSASSS scores were acquired; Anti-Sacchoromyces Cervesiae Antibodies (ASCA) was measured with ELISA

Complete rheumatological examination, evaluated via the ESSG criteria for SpA. Analyzed HLAB27, B51 C ANCA.

\section{Outcomes and Results}

Upregulation of autophagy genes were observed in $A S$ and $C D$ patients. Autophagy was also required to modulate expression of LPMCS. This suggests that misfolding of HLA-B27 occurs in the gut of AS patients and in accompanied by the activation of autophagy. Autophagy (not UPR) is associated with the increased expression of IL-23 in AS patients.

Juvenile-Onset was characterized by male gender, peripheral involvement (arthritis), positive HLA-B27 vs adult-onset was associated with inflammatory bowel disease, dactylitis and nail involvement.

The two markers showed no association between polymorphisms and AS susceptibility, however significant association was seen between 12912 and inflammatory bowel disease.

Cal protectin levels were elevated in $41 \%$ of AS patients. fCAL-positive AS patients displayed higher IBD antibodies. Further studies needed to determine whether fCAL can be used to identify a subgroup of AS patients with IBD.

Cender, family history, presence of peripheral arthritis and IBD were consistent across all three groups. Brazilians had higher MASE score and worse performance on the quality of life questionnaire.

Prevalence of self-reported articular symptoms exceeds $40 \%$, with $9.5 \%$ incidence in 1 year follow up.

Eleven AS patients were AGA positive (o controls); 3 were also EMA positive. Destruction of villi was seen the in three ACA/EMA positive patients. AGA positivity might contribute to pathogenesis of AS (increasing intestinal permeability), more research is required.

$40 \%$ of patients had evidence of sacroiliitis, 5 fulfilled the criteria for AS. No association of HLA with sacroilitis, but definitely with AS. Possession of HLA-B27 conveys an increased risk of developing axial inflammation in $C D$.

Increased prevalence of ASCA in AS and undifferentiated SPA. ASCA can also be a marker for radiological damage and more severe course AS.

Prevalence of SpA and AS in IBD $-45.7 \%$ व $9.9 \%$. High prevalence of asymptomatic sacroiliitis in $\mathrm{IBD}$, an early diagnosis of inflammatory arthritis could prevent a disability due to SpA and AS.

BASDAl=Bath Ankylosing Spondylitis Disease Activity Index; BASRI=Bath Ankylosing Spondylitis Radiology Index; ELISA=enzyme-linked immunosorbent assay; ESSC=European Spondyloarthropathy Studies Group; GWAS=genome-wide association study; IHC=immunohistochemistry; MASE=Maastricht Ankylosing Spondylitis Enthesitis Score; MRI=magnetic resonance imaging; mSASSS=modified Stoke Ankylosing Spondylitis Spinal Score; RT-PCR=reverse transcription polymerase chain reaction. 
Table 2. Criteria Used to Evaluate Study Quality

\begin{tabular}{ll}
\hline 0 & Preclinical studies- including experimental studies and animal models \\
\hline 1 & Randomized controlled trials \\
\hline 2 & Non-randomized controlled trial - a prospective (pre-planned) study with a predetermined eligibility criteria and outcome measures \\
\hline 3 & Observational studies with controls- includes retrospective, case-control studies, and cohort studies \\
4 & Observational studies without controls - includes cohort studies without controls, case series without controls, case studies without control \\
\hline
\end{tabular}

Figure 2. Flow Diagram for Article Selection

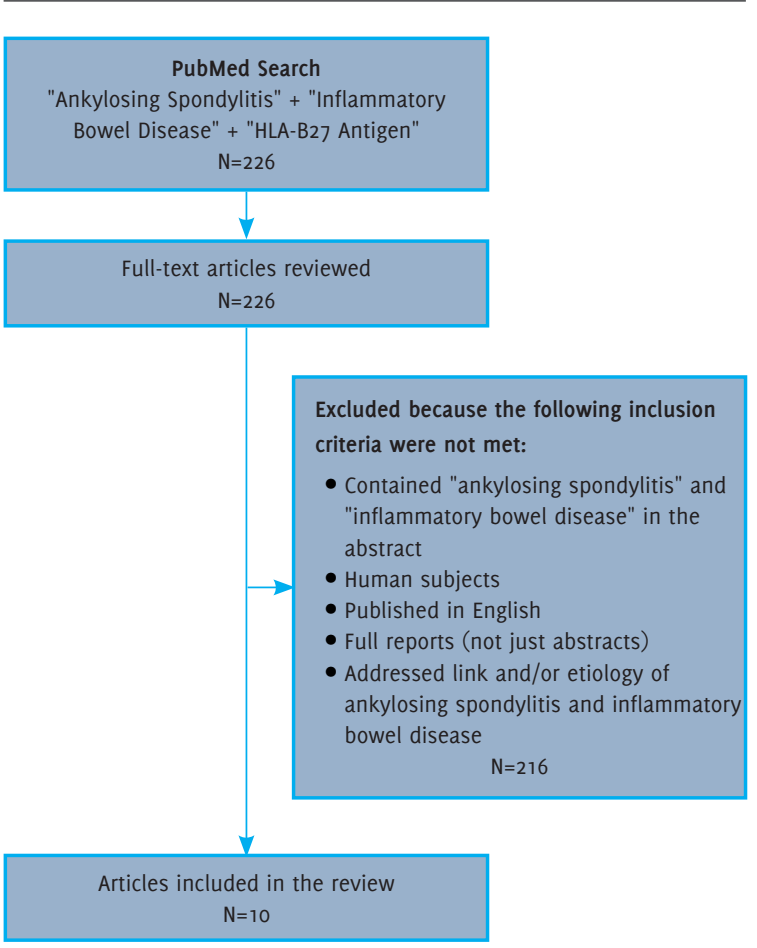

protein response (UPR) were evaluated in mononuclear cells of the lamina propria by reverse transcription polymerase chain reaction. The researchers noted upregulation of protein expression in the autophagy pathway via LC 311, ATG 5 and ATG 12 $\left(r^{2}=0.66,0.68,0.77\right.$ respectively, $\left.p<0.0001\right)$. However, no significant expression of UPR genes, namely HSPA5, was observed when compared to controls ( $p<0.0001)$. This research suggested that misfolding of HLA-B27 in the gut mucosa and modulation of IL23 is associated with autophagy rather than UPR.

\section{Potential IBD \& AS Biomarkers}

\section{Anti-Sacchoromyces cervesiae Antibodies (ASCA)}

Aydin et al measured anti-Sacchoromyces cervesiae antibodies, a characteristic marker of $C D$, and Bath Ankylosing Spondylitis Disease Activity Index (BASDAI), a common self assessment used in AS diagnosis, in 175 AS patients, 47 undifferentiated spondyloarthropathy (USpA) patients, an incomplete or early form of a definitive seronegative spondyloarthropathy, and 103 healthy controls. ${ }^{6}$ There was an increased prevalence of ASCA in patients with AS and USpA ( $p<0.0008, p<0.02$ respectively), however no correlation was seen between ASCA and erythrocyte sedimentation rate (ESR), C-Reactive Protein (CRP) and BASDAI scores ( $p=0.75,0.79,0.28$ respectively). ASCA-positive patients also required anti TNF-alpha therapy more often
( $p<0.006)$. This study failed to show any correlation with ASCA and $\mathrm{HLA}-\mathrm{B} 27(\mathrm{p}=1)$.

\section{Fecal Calprotectin}

Matzkies et al conducted a pilot study to measure fecal calprotectin (fCal), a biochemical marker for intestinal wall inflammation, and other IBD-related serology (ASCA, ANCA, anti-0mpC, anti-CBir1 and anti-12) in 39 AS patients and 42 controls. ${ }^{33}$ AS patients were mostly male and $76 \%$ were HLA positive. The fCal levels were significantly higher in the AS group ( $p<0.0002$ ), as were ANCA, ASCA, and anti-CBir1 ( $p<0.001,0.023,0.003$ respectively). The fCal-positive AS patients also demonstrated higher titers of IBD antibodies, namely IgA ASCA, IgG ASCA and CBir1 $(p<0.05,0.003,0.002$ respectively) and higher BASDAl scores $(p=0.016)$. However, no correlation was shown between the presence of the HLA allele and high fCal levels $(p=0.71)$.

\section{Anti-endomysial (EMA) and Anti-gliadin (AGA) Antibodies}

Togrol et al analyzed 30 AS patients and 19 controls with basic clinical serology for HLA-B27, AGA and EMA, both IgG and IgA antibody subtypes. ${ }^{34}$ Radiological assessment was also performed on all subjects. Gastroduodenoscopy was only performed on AGA-positive patients. Only 11 of the 30 AS patients were positive for AGA ( $p<0.001)$, and three of 30 were positive for EMA, while none of the controls were positive for either antibody. No correlation was found between presence of AGA and severity of AS.

\section{Relevance of Ethnicity}

Skare et al evaluated 1318 consecutive patients with spondyloarthropathies (SpA), in 29 different referral centers throughout Brazil.35 They compared and contrasted the disease expressivity and variance of SpA among different ethnic backgrounds. This was achieved through a standard protocol of investigation outlined by the researchers, whereby information was retrieved from patient interviews and multiple self-assessment scores (BASDAI, BASFI, AS quality of life questionnaire etc.). The physical exam was guided through many standardized scores and activity indices, such as the Bath Ankylosing Spondylitis Metrology Index (BASMI) and the Maastricht Ankylosing Spondylitis Enthesitis Score (MASES). In the cohort, $65 \%$ of patients were white (compared to the general population of $48.7 \%$ ), $31 \%$ were African-Brazilian and $3.7 \%$ were of other ethnicities. White patients presented with more psoriasis and linkage to HLA-B27 ( $p=0.002,0.014$ respectively). African-Brazilian patients reported worse back pain and hip involvement $(p=0.041,0.020$ respectively) in addition to a lower patient global assessment and a lower quality of life $(p=0.011$, $<0.0001$ respectively). HLA-negative patients were characterized as having no family history, later disease onset and limited extra-articular manifestations. However, no statistical data was provided for these statements. 
Table 3. Candidate Genes and Biomarkers Outlined in This Review

\begin{tabular}{|c|c|c|}
\hline $\begin{array}{l}\text { Candidate Genes/ } \\
\text { Biomarkers }\end{array}$ & Relevance & Future direction \\
\hline HLA-B27 & $\begin{array}{l}90 \% \text { link to AS. Current understanding: Misfolding } \\
\text { of B2 leads to intracellular accumulation } \rightarrow \text { stress/ } \\
\text { inflammatory response }\end{array}$ & More research needed to understand the exact mechanism \\
\hline IL23/Th17 & $\begin{array}{l}\text { Upregulation of Th17 cells via IL } 23 \rightarrow \text { development } \\
\text { of autoimmune conditions }\end{array}$ & $\begin{array}{l}\text { Considered to be a gene of current major research interest. Overlap seen } \\
\text { between AS and IBD pathogenesis. May indicate autoimmune mechanism }\end{array}$ \\
\hline ASCA & Currently used in cystic fibrosis and liver cirrhosis & $\begin{array}{l}\text { Extensive variability in the literature. More sensitive and specific assays } \\
\text { required }\end{array}$ \\
\hline fCal & Higher titers found in patients with IBD symptoms & $\begin{array}{l}\text { Inconclusive. Consider conducting case control studies with patients on } \\
\text { TNF inhibitor a NSAID therapy }\end{array}$ \\
\hline
\end{tabular}

HLAB27=human leukocyte antigen B27; Th17=T helper 17 cells; IL23=interleukin-23; ERAP-1=endoplasmic reticulum aminopeptidase-1; ASCA=anti-Sacchoromy-

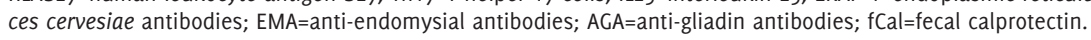

A second ethnic study, conducted by Wei et al (2013) investigated genes unveiled in the European based genome-wide association study of AS, specifically EDIL3, HAPLN1 and ANO6 at 12912 and their association to AS..$^{36}$ The study included 475 AS patients and 475 controls, $90.7 \%$ of the AS patients were HLA-B27-positive. They used genetic markers for the relevant genes, along with multiple AS activity indices and relevant physical exam findings to compare patients. In the Taiwanese population, EDIL3, HAPLN 1 and ANO6 demonstrated no link to AS ( $p=0.3033,0.6754,0.5266$ respectively), however there was a significant association found between AN06 and IBD ( $p=0.0131)$.

\section{IBD Patients with Joint Manifestations}

Turkcapar et al evaluated 162 adult patients with either Crohn's disease (CD) or ulcerative colitis (UC) for spondyloarthropathy $(\mathrm{SpA})$ by a full rheumatological assessment and radiography. ${ }^{2}$ HLA-B27, B51 and anti-neutrophil cytoplasmic antigen (ANCA) were also tested in all patients. The prevalence of IBD and SpA was $45.7 \%$. They found that the HLA-B27 allele was more common in the patients with sacroiliitis, peripheral arthritis and enthesitis ( $p<0.001$ for all). Additionally, $13.6 \%$ of patients exhibited no musculoskeletal manifestations on physical examination, but were determined to have grade-2 sacroiliitis on computer tomography (CT) and radiographs.

Another study by Orchard et al (2009) investigated 44 patients with $C D$ in a prospective study. ' They evaluated the patients' presenting symptoms, rheumatology profile and HLA status and conducted a radiologic evaluation of the patients' sacroiliac joints. The researchers found that 17 of the 44 patients had evidence of sacroiliitis, HLA-B27 was present in seven of 44 patients $(15.9 \%)$, all of whom had sacroiliitis and five of whom had AS ( $p<0.001)$. Sacroiliitis appeared to be a common extra-intestinal manifestation of $C D$, but HLA-B27 was not associated with isolated sacroiliitis $(p=0.057)$. Conversely, HLA-B27 could be considered an important risk factor for developing axial SpA in CD, as $100 \%$ of patients with this allele in this study developed sacroiliitis.

In a final IBD study, D'Inca et al surveyed 651 patients over a 12-month period to determine which extra-intestinal symptoms were apparent in IBD patients. ${ }^{37}$ Articular pain was reported most frequently, totaling 262 patients, specifically 142 patients with UC and 120 patients with CD. These 262 patients were further evaluated by rheumatologists for HLA type, degree of joint involvement (axial or peripheral) and followed up 12 months after the initial survey. HLA-B27 was present in five of the participants, three of whom had AS. The frequency of HLA-B27 was significantly higher in the subgroup of patients with axial arthropathy compared to peripheral arthropathy $(O R=13.1$, p $<0.00001)$. Arthropathies were axial in $53 \%$, and polyarticular in $23 \%$ of patients. Of the $40.2 \%$ of patients who reported arthralgia in the original survey, only $9.5 \%$ reported symptoms during the 12-month follow up.

\section{Discussion}

In this review, the relationship between IBD and AS was examined. There is a significant overlap between these two diseases, with IBD being the most common extra-articular symptom in AS and arthralgia being the most common extra-intestinal symptom in IBD. It nevertheless remains questionable whether there is a causal relationship between IBD and AS. It is apparent that the inheritance of HLA-B27 does not definitively determine whether a person will develop AS, as only $1-2 \%$ of the population that is HLA-B27 positive ends up developing AS. There is, however, a more significant link between the presence of the HLA-B27 allele and a concurrent diagnosis of IBD. Studies show that the majority of patients with IBD and the HLA-B27 allele will also present with sacroiliitis.? They suggest that gut inflammation in combination with HLA-B27 almost guarantees a subsequent diagnosis of AS.

Many of the studies included in this review used a cross-sectional design, which limits the interpretation of causal relationships in AS. ${ }^{35,36}$ It allows the researchers to note associations but denies the ability to sequence events in disease etiology. A Brazilian study juxtaposes epidemiologic variables between two age groups: juvenile (younger than 16 years of age) and adult-onset (greater than 16 years of age) spondyloarthropathy. Findings indicate that male gender and HLA-B27 are more common in younger patients, whereas IBD and cutaneous psoriasis are more common in adult-onset SpA. One could extrapola- 
te from this study that IBD is a latter manifestation of SpA, however this is a cross-sectional design. ${ }^{37}$ Further longitudinal investigations that evaluate associations between genetic and environmental risk factors would contribute immensely to understanding the complete pathogenesis.

The advantage of cross-sectional studies is that researchers can reach a more diverse population and may also expose associations that serve as a starting point for other, more focused studies. This was observed in the two studies that analyzed the effect of ethnicity on the clinical presentation of AS. One unveiled the difference in candidate gene expression seen in European versus Taiwanese populations, whereas the other highlighted the variation in symptoms among different ethnicities in Brazil. 35,36 The results of these studies suggest that the pathogenesis for AS may be unique in each ethnic group and that GWAS conducted in one population is not transferable to another. Further evidence of this was demonstrated by one researcher who noted that the HLA-B27 allele was found in $80 \%$ of white patients compared to $60 \%$ of black patients. ${ }^{35}$ Countries with a mixed demographic may need to take this into consideration when conducting studies or determining treatment options for patients from different ethnic backgrounds.

Many studies included in this review involved a sample population that was identified based on a recent visit to the rheumatologist. $733,34,36$ However, many developing nations do not have equal access to health care, therefore, patients involved in these studies may be more representative of urban or higher social class. ${ }^{35}$ It is, therefore, critical that adequate representation from all social demographics be included in studies, to gain the best possible understanding of disease manifestation and treatment protocol.

Another shortcoming of many studies is the small sample size and concomitant lack of statistical power. Determinants of statistical power include sample size, statistical significance criteria ( $p$-values) and magnitude of effect. One study referenced an odds ratio of 13.1 and $p<0.00001$ with regard to the HLA-B27 allele and the symptoms of axial arthropathy. ${ }^{38}$ Both of these values exhibit undeniable statistical significance. However, this result was based on a mere five patients in the study with HLA-B27. Despite the statistical significance of this study, the small sample size raises questions about the applicability of the results to the broader population. Similarly, other studies had sample groups with fewer than 40 participants.33,34 Larger studies are required to determine concrete relationships.

Multiple studies have investigated the use of selective biomarkers in AS patients. ${ }^{6,33,34}$ The diagnosis of AS is currently made through a combination of physical examination, history and radiography, however, due to the mixed clinical presentation and delayed evidence on radiography, AS is commonly misdiagnosed or delayed in diagnosis by 5-6 years. ${ }^{2}$ Accurate and early diagnosis of the disease would allow a treatment regime designed to delay fusion of vertebrae, stiffening of joints and debilitating effects of AS. Biomarkers would allow for more precise direction with prognosis and management. ${ }^{39}$

The anti-ASCA antibody showed higher titers in patients with more symptoms of AS, but no correlation with the HLA-B27 alle- le. Anti-ASCA is also used in the evaluation of patients with liver cirrhosis, cystic fibrosis and Behcet's disease. ${ }^{6}$ There appears to be extensive variability in the literature as some studies demonstrated no correlation between anti-ASCA and SpA, others limit the association to $\lg A$ not $\lg \mathrm{G}$, and some claim it is seen in AS but not uSpA. ${ }^{00-42}$ The discrepancy of results may be due to the variation in sensitivity and specificity in assays. More consistent and reproducible results need to be established before anti-ASCA could be considered a valid biomarker for AS.

Another biomarker, $\mathrm{fCal}$, showed higher titers in patients with IBD symptoms, but no relevant association to the HLA allele. ${ }^{33}$ This study purposely excluded patients that were on TNF-alpha inhibitor or non-steroidal anti-Inflammatory drugs (NSAID), with the consideration that NSAIDS can increase gut permeability and that TNF inhibitors may alter gut inflammation..$^{33}$ Other studies that investigated fCal did not use these exclusion criteria and concluded that there was no correlation between $\mathrm{fCal}$ and gut inflammation, and high levels of fCal were associated with age, disease duration, raised ESR and serum calprotectin levels, but not with GI symptoms. ${ }^{43}$ This exclusion criterion may limit the applicability of results to the general population, as most patients with AS or underlying gut pathology will likely be on some sort of therapy. The exclusion of this demographic from the study, therefore, reduces the relevance and application of the results in the clinical setting. Future studies may consider evaluating the levels of $\mathrm{fCal}$ in both the presence and absence of TNF inhibitors and NSAIDS to gain a better understanding of how this marker fluctuates with treatment regimen and flare-ups of IBD.

The final biomarkers uncovered in this review were anti-AGA and anti-EMA, two antibodies commonly used in celiac disease. Researchers determined that anti-AGA was higher in the AS group, and also found that three patients who were anti-EMA-positive were also anti-AGA-positive. This study lacked statistical power as it analyzed only 30 patients. Its analysis was skewed, as gastroduodenoscopy and mucosal biopsy was only performed on the 11 patients who were AGA positive, whereas all other negative anti-AGA patients in the AS group and the entire control group were limited to serological analysis. Researchers claim that increased inflammatory cell infiltrate was seen in the lamina propria of anti-AGA/EMA-positive patients. However, they did not have a control group for comparison. Anti-AGA antibodies may be an indicator of AS pathogenesis by increasing intestinal permeability, but it does not appear to be specific to AS as only 11 of 30 patients had a positive titer. A larger cohort is required to validate these associations.

Current research is heavily focused on understanding the genetic link to AS and how certain genes play a role in the pathogenesis, but not necessarily on the exact link between the symptoms of IBD and AS. A limitation to this review is that it is based on a key word search of the literature, and although IBD and HLA-B27 are brought up consistently in research relating to AS, it is uncommon to find a directed study on the relation between the two. However, this is an inherent limitation of the searching capability of research databases. An example of this can be seen in the three studies included in this review, all of which targeted a population of subjects with IBD, but then looked at the prevalence of associated arthralgia. ${ }^{2,7,38}$ Converse- 
ly, the main goal of this paper was to do the opposite: evaluate the likelihood of AS patients having symptoms of IBD. Given that this kind of study provides the greatest insights regarding this relationship to date, more directed studies looking specifically at AS patients need to be undertaken for a clear consensus to be reached.

\section{Future Directions Pharmaceuticals}

Current treatment of AS includes both pharmacological and non-pharmacological approaches. Pharmacological intervention normally includes NSAIDS, disease modifying anti-rheumatic drugs (DMARDS) and TNF-alpha inhibitors. Review of TNF-alpha inhibitor therapy has demonstrated that $40 \%$ of AS patients experience an increase in function, reduction in pain and morning stiffness and overall well-being. ${ }^{44}$ Further advances in pharmacologic treatment are limited to a full comprehension of $\mathrm{AS} \mathrm{pa-}$ thogenesis, predisposing genes and environmental factors, as this enables manufacturers to target more disease-specific culprits. As an example, the more conclusive evidence of IL23R's role in AS has allowed researchers to manufacture an IL23 specific monoclonal antibody which is currently undergoing phase two clinical trials. ${ }^{18}$

\section{Genetics}

Studies have confirmed the role of IL23R in AS aetiopathogenesis, and suggested that this pathway may be a key regulator in the misfolding of the HLA-B27 protein. ${ }^{13}$ Previous studies suggested that misfolding was due to an unfolded protein response (UPR) in the cell, however this study proved that it was due to upregulation of autophagy. Additionally, they localized the misfolding of HLA-B27 to the gut, which further confirms the suspicion that chronic gut inflammation may be a contributor to the early pathogenesis of AS.

Other genes such as ERAP were not discussed in this review, as they did not appear in the search criteria. The development of AS is multifactorial and may even be unique in each patient, therefore, careful accreditation of all genetic markers unveiled in the GWAS is necessary in future research.

\section{GIT Therapy}

Not all AS patients suffer from IBD, but a large majority have subclinical gut inflammation. Treatment of this could be a future consideration for clinicians. Multiple studies have identified bacteria such as Klebsiella, Yersinia, and most recently Faecali- bacterium prausnitzii and Bacteroides fragilis in AS patients. ${ }^{45}$ A potential route of treatment is fecal microbiota transfer (FMT) - replacement of missing or overbearing bacteria to the natural multicomponent state. FMT is considered a highly effective treatment for Clostridium difficile, and was recently accepted by the Food at Drug Administration (FDA) as an experimental therapy. It has shown variable effectiveness in the treatment of IBD, however, the success in AS is still under review. ${ }^{46}$ Furthermore, a pediatric study on IBD concluded that certain microbiota are more responsive to TNF therapy and that the levels of certain bacteria could be used as a predictor of responsiveness to TNF therapy. ${ }^{47}$

An alternative, less invasive, manipulation of the gut microbiota involves the alteration of diet through supplementation and probiotics. ${ }^{22}$ Probiotics improve colitis and IBD symptoms in murine models and human subjects due to their induction of TLR9 and resulting anti-inflammatory effect. ${ }^{48,49}$ Adjusting an AS patient's diet could be used as a complement to conventional pharmaceuticals in the future.

\section{Radiography}

Due to the variation in clinical presentation, AS is a challenging arthropathy to diagnose. It may be possible to diagnose AS earlier if younger patients with IBD are screened for signs of spondyloarthropathy. ${ }^{2}$ A full radiological and rheumatological assessment could drastically reduce the progression and potential disability of SpA.

\section{Conclusion}

This review supplements current evidence that there is a link between IBD and AS. Many studies prove the predisposition of IBD patients with HLA-B27 to developing symptoms of sacroiliitis and AS. However, HLA-B27 is considered to be one of many factors in the disease, not the sole contributor. More longitudinal studies need to be conducted to clarify whether AS and IBD are concomitant or causal of one another. Similarly, larger cohorts should be considered to increase the power and relevance of the studies. The complex pathogenesis, polygenic etiology and variance between ethnicities of AS has proven to be an obstacle and major focus of research. The discovery of more specific biomarkers is essential for the early diagnosis of AS and a deeper understanding of the exact pathogenesis will allow for more directed and effective treatment for this incapacitating disease. 


\section{References}

1. Golder V, Schachna L. Ankylosing spondylitis: an update. Aust Fam Physician. 2013 Nov;42(11):780-4.

2. Turkcapar N, Toruner M, Soykan I, Aydintug OT, Cetinkaya H, Duzgun N, et al. The prevalence of extraintestinal manifestations and HLA association in patients with inflammatory bowel disease. Rheumatol Int. 2006 May;26(7):663-8. 3. Tsui FW, Tsui HW, Akram A, Haroon N, Inman RD. The genetic basis of ankylosing spondylitis: new insights into disease pathogenesis. Appl Clin $\mathrm{Ge}$ net. 2014 May 22;7:105-15.

4. De Vos M. Joint involvement associated with inflammatory bowel disease. Dig Dis. 2009;27(4):511-5.

5. Rudwaleit M, Baeten D. Ankylosing spondylitis and bowel disease. Best Pract Res Clin Rheumatol. 2006 Jun;20(3):451-71.

6. Aydin SZ, Atagunduz P, Temel M, Bicakcigil M, Tasan D, Direskeneli H. Anti-Saccharomyces cerevisiae antibodies (ASCA) in spondyloarthropathies: a reassessment. Rheumatology (0xford). 2008 Feb;47(2):142-4.

7. Orchard TR, Holt H, Bradbury L, Hammersma J, MCNally E, Jewell DP, et al. The prevalence, clinical features and association of HLA-B27 in sacroilitis associated with established Crohn's Disease. Aliment Pharmacol Ther. 2009 Jan;29(2):193-7.

8. Jacques $P$, Elewaut $D$. Joint expedition: linking gut inflammation to arthritis. Mucosal Immunol. 2008 Sep;1(5):364-71.

9. Steer S, Jones H, Hibbert J, Kondeatis E, Vaughan R, Sanderson J, et al. Low back pain, sacroiliitis, and the relationship with HLA-B27 in Crohn's disease. J Rheumatol. 2003 Mar;30(3):518-22.

10. Cho JH. The genetics and immunopathogenesis of inflammatory bowel disease. Nat Rev Immunol. 2008 Jun;8(6):458-66.

11. Brown MA, Kennedy LC, MacGregor AJ, Darke C, Duncan E, Shatford JL, et al. Susceptibility to ankylosing spondylitis in twins: the role of genes, HLA, and the environment. Arthritis Rheum. 1997 0ct;40(10):1823-8.

12. Jarvinen P. Occurrence of ankylosing spondylitis in a nationwide series of twins. Arthritis Rheum. $1995 \mathrm{Mar} ; 38(3): 381-3$.

13. Ciccia F, Accardo-Palumbo A, Rizzo A, Guggino G, Raimondo S, Giardina A, et al. Evidence that autophagy, but not the unfolded protein response, regulates the expression of IL-23 in the gut of patients with ankylosing spondylitis and subclinical gut inflammation. Ann Rheum Dis. 2014 Aug;73(8):1566-74.

14. Haroon N. Endoplasmic reticulum aminopeptidase 1 and interleukin-23 receptor in ankylosing spondylitis. Curr Rheumatol Rep. 2012 0ct; 14(5):383-9. 15. Davis JC Jr. Understanding the role of tumour necrosis factor inhibition in ankylosing spondylitis. Semin Arthritis Rheum. 2005 Feb;34(4):668-77.

16. Korn T, Bettelli E, Oukka M, Kuchroo VK. IL-17 and TH17 cells. Annu Rev Immunol. 2009;27:485-517.

17. Smith JA, Colbert RA. Review: the interleukin-23/interleukin 17 axis in spondyloarthritis pathogenesis: $\mathrm{TH} 17$ and beyond. Arthritis Rheumatol. 2014 Feb;66(2):231-41.

18. Baeten D, Baraliakos X, Braun J, Sieper J, Emery P, van der Heijde D, et al. Anti-interleukin-17A monoclonal antibody secukinumab in treatment of ankylosing spondylitis: a randomised, double-blind, placebo-controlled trial. Lancet. 2013 Nov;382(9906):1705-13.

19. Evans DM, Spencer CC, Pointon JJ, Su Z, Harvey D, Kochan C, et al. Interaction between ERAP1 and HLA-B27 in ankylosing spondylitis implicates peptide handling in the mechanism for HLA-B27 in disease susceptibility. Nat Genet. 2011 Jul 10;43(8):761-7.

20. Tsai WC, Chen CJ, Yen JH, Ou TT, Tsai JJ, Liu CS, et al. Free HLA class I heavy chain-carrying monocytes-a potential role in the pathogenesis of spondyloarthropathies. J Rheumatol. 2002 May;29(5):966-72.

21. Kollnberger S, Chan A, Sun MY, Chen LY, Wright $C$, di Cleria K, et al. Interaction of HLA-B27 homodimers with KIR3DL1 and KIR3DL2, unlike HLA-B27 heterotrimers, is independent of the sequence of bound peptide. Eur J Immunol. 2007 May;37(5):1313-22.

22. Ebringer A, Rashid T, Tiwana H, Wilson C. A possible link between Crohn's disease and ankylosing spondylitis via Klebsiella infections. Clin Rheumatol. 2007 Mar;26(3):289-97.

23. Ebringer A, Rashid T, Wilson C, Ptaszynska,T, Fielder M. Ankylosing spondylitis, HLA-B27 and Klebsiella - an overview: proposal for early diagnosis and treatment. Curr Rheumatol Rev. 2006;2(1):55-68.

24. Wilson C, Rashid T, Tiwana H, Beyan H, Hughes L, Bansal S, et al. Cytotoxicity responses to peptide antigens in rheumatoid arthritis and ankylosing spondylitis. J Rheumatol. 2003 May;30(5):972-8.

25. Faustini F, Zoli A, Ferraccioli CF. Immunologic and genetic links between spondyloarthropathies and inflammatory bowel diseases. Eur Rev Med Pharmacol Sci. 2009 Mar;13 Suppl 1:1-9.

26. Martínez-Conzález 0, Cantero-Hinojosa J, Paule-Sastre P, Gómez-Magán JC, Salvatierra-Ríos D. Intestinal permeability in patients with ankylosing spondylitis and their healthy relatives. Br J Rheumatol.1994 Jul;33(7):644-7.

27. Demetter P, Baeten D, De Keyse F, De Vos M, Van Damme N, Vebruggen C, et al. Subclinical gut inflammation in spondyloarthropathy patients is associated with upregulation of the E-cadherin/catenin complex. Ann Rheum Dis. $2000 \mathrm{Mar} ; 59(3): 211-6$.

28. De Rycke L, Vandooren B, Kuithof E, De Keyser F, Veys EM, Baeten D. Tumour necosis factor alpha blockade treatment down-modulates the increased systemic and local expression of Toll-like receptor 2 and Toll-like receptor 4 in spondylarthropathy. Arthritis Rheum. 2005 Jul;52(7):2146-58.

29. Yang ZX, Liang Y, Zhu Y, Li C, Zhang LZ, Zeng XM, et al. Increased expression of Toll-like receptor 4 in peripheral blood leucocytes and serum levels of some cytokines in patients with ankylosing spondylitis. Clin Exp Immunol. 2007 Jul; 149(1):48-55.

30. Cauli A, Piga M, Dessole G, Porru G, Floris A, Vacca A, et al. Killer-cell immunoglobulin-like receptors (KIR) and HLA-class I heavy chains in ankylosing spondylitis. Drug Dev Res. 2014 Nov;75 Suppl 1:S15-9.

31. Haroon N, Tsui FW, Uchanska-Ziegler B, Ziegler A, Inman RD. Endoplasmic reticulum aminopeptidase 1 (ERAP1) exhibits functionally significant interaction with HLA-B27 and relates to subtype specificity in ankylosing spondylitis. Ann Rheum Dis. 2012 Apr;71(4):589-95.

32. Lopez-Larrea C, Blanco-Celaz MA, Torre-Alonso JC, Bruges Armas J, Suarez-Alvarez $B$, Pruneda $L$, et al. Contribution of $K_{1 R 3} D_{1} / 3 D S_{1}$ to ankylosing spondylitis in human leukocyte antigen-B27 Caucasian populations. Arthritis Res Ther. 2006;8(4):R101.

33. Matzkies FG, Targan SR, Berel D, Landers C], Reveille JD, McGovern DP, et al. Markers of intestinal inflammation in patients with ankylosing spondylitis: a pilot study. Arthritis Res Ther. 2012 Nov;14(6):R261.

34. Togrol RE, Nalbant S, Solmazgül E, Ozyurt M, Kaplan M, Kiralp MZ, et al. The significance of coeliac disease antibodies in patients with ankylosing spondylitis: a case-controlled study. J Int Med Res. 2009 Jan-Feb;37(1):220-6. 35. Skare TL, Bortoluzzo AB, Gonçalves CR, Braga da Silva JA, Ximenes AC, Bértolo $M B$, et al. Ethnic influence in clinical and functional measures of Brazilian patients with spondyloarthritis. J Rheumatol. 2012 Jan;39(1):141-7.

36. Wei JC, Hsu YW, Hung KS, Wong RH, Huang CH, Liu YT, et al. Association study of polymorphisms rs4552569 and rs17095830 and the risk of ankylosing spondylitis in a Taiwanese population. PLoS One. 2013;8(1):e52801

37. Duarte AP, Marques CD, Bortoluzzo AB, Gonçalves CR, da Silva JA, Ximenes $A C$, et al. [Epidemiologic profile of juvenile-onset compared to adult-onset spondyloarthritis in a large Brazilian cohort]. Rev Bras Reumatol. 2014 NovDec;54(6):424-30. Portuguese

38. D'Incà R, Podswiadek M, Ferronato $A$, Punzi L, Salvagnini M, Sturniolo GC. Articular manifestations in inflammatory bowel disease patients: a prospective study. Dig Liver Dis. 2009 Aug;41(8):565-9.

39. Tsui FW, Tsui HW, Las Heras F, Pritzker KP, Inman RD. Serum levels of novel noggin and sclerostin-immune complexes are elevated in ankylosing spondylitis. Ann Rheum Dis. 2014 0ct;73(10):1873-9.

40. Riente L, Chimenti D, Pratesi F, Delle Sedie A, Tommasi S, Tommasi C, et al. Antibodies to tissue transglutaminase and Saccharomyces cerevi- 


\section{Review}

siae in ankylosing spondylitis and psoriatic arthritis. J Rheumatol. 2004 May;31(5):920-4.

41. Hoffman IE, Demetter P, Peeters M, De Vos M, Mielants H, Veys EM, et al. Anti-saccharomyces cerevisiae IgA antibodies are raised in ankylosing spondylitis and undifferentiated spondyloarthropathy. Ann Rheum Dis. 2003 May;62(5):455-9.

42. Torok HP, Glas J, Gruber R, Brumberger V, Strasser C, Kellner H, et al. Inflammatory bowel disease-specific autoantibodies in HLA-B27-associated spondyloarthropathies: increased prevalence of ASCA and pANCA. Digestion. 2004;70(1):49-54.

43. Klingberg E, Carlsten H, Hilme E, Hedberg M, Forsblad-d'Elia H. Calprotectin in ankylosing spondylitis-frequently elevated in feces, but normal in serum. Scand J Gastroenterol. 2012 Apr;47(4):435-44.

44. Maxwell LJ, Zochling J, Boonen A, Singh JA, Veras MM, Tanjong Chogomu E, et al. TNF-alpha inhibitors for ankylosing spondylitis. Cochrane Database Syst Rev. 2015 Apr 18;4:CD005468.
45. Stoll ML, Kumar R, Morrow CD, Lefkowitz EJ, Cui X, Genin A, et al. Altered microbiota associated with abnormal humoral immune responses to commensal organisms in enthesitis-related arthritis. Arthritis Res Ther. 2014 Nov; 16(6):486.

46. Colman RJ, Rubin DT. Fecal microbiota transplantation as therapy for inflammatory bowel disease: a systematic review and meta-analysis. J Crohns Colitis. 2014 Dec;8(12):1569-81.

47. Kohlo KL, Korpela K, Jaakkola T, Pichai MV, Zoetendal EG, Salonen A, et al. Fecal microbiota in pediatric inflammatory bowel disease and its relation to inflammation. Am J Gastroenterol. 2015 Jun;110(6):921-30.

48. Karimi 0, Peña AS. Indications and challenges of probiotics, prebiotics, and symbiotics in the management of arthralgias and spondyloarthropathies in inflammatory bowel disease. J Clin Gastroenterol. 2008 Sep;42 Suppl 3 Pt 1:S136-41.

49. Lee J, Rachmilewitz D, Raz E. Homeostatic effects of TLR9 signaling in experimental colitis. Ann N Y Acad Sci. 2006 Aug;1072:351-5.

\section{Acknowledgments}

The author would like to thank Saba University School of Medicine for endorsing the publication of this review article.

Conflict of Interest Statement at Funding

The authors have no funding, financial relationships, or conflicts of interest to disclose.

\section{Author Contributions}

Conceptualization, Critical revision of the manuscript, Approval of the final version: JR, MG. Data collection, Data analysis and interpretation, Writing: JR. Administrative/technical advice: MG.

Cite as:

Rivington J, Gillett M. Establishing a causal link between ankylosing spondylitis and inflammatory bowel disease: a review of the literature. Int J Med Students. 2016 May-Aug;4(2):55-63. 